University of Warwick institutional repository

This paper is made available online in accordance with

publisher policies. Please scroll down to view the document

itself. Please refer to the repository record for this item and our

policy information available from the repository home page for

further information.

To see the final version of this paper please visit the publisher's website.

Access to the published version may require a subscription.

Author(s): Page, Edward

Article Title: Equity and the Kyoto Protocol

Year of publication: 2007

Link to published version: http://dx.doi.org/10.1111/j.1467-9256.2007.00273.x

Publisher statement: The definitive version is available at www.blackwell-synergy.com 


\section{EQUITY AND THE KYOTO PROTOCOL}

Global climate change raises a number of important issues for political scientists and theorists. One issue concerns the ethics of implementing policies that seek to manage the threats associated with dangerous climate change in order to protect the interests of future generations. The focus of much of the debate about climate change and intergenerational equity is the United Nations Framework Convention on Climate Change (FCCC) and the Kyoto Protocol to this Convention. This article outlines the mechanisms adopted by the Kyoto Protocol and three rival 'climate architectures', evaluating each in terms of some basic principles of equity.

\section{Introduction}

Global climate change raises a number of important questions for political scientists and theorists. International relations scholars have examined the complex negotiations amongst states aimed at reducing emissions of greenhouse gases such as carbon dioxide $\left(\mathrm{CO}_{2}\right)$, as well as the human and national security implications of global climate change (Barnett, 2002; Stripple, 2005). International political theorists have explored the normative problems raised by the fact that the impacts of climate change are expected to bear much more heavily on the developing world, which has contributed little to climate change (Shue, 2001; Caney, 2005). Meanwhile, scholars of intergenerational equity have outlined a series of conceptual problems that complicate the idea that earlier generations are obliged to adopt policies of mitigation (to prevent avoidable climate changes) or adaptation (to modify human practices to accommodate climate changes that are unavoidable) for the benefit of later generations (Gardiner, 2004; Page, 2006, pp.99-160).

The point of intersection for many of the above debates has been the Kyoto Protocol on Climate Change, which was adopted in December 1997 and later amended at several 'Conferences of the Parties' (COPs). In this paper, I offer a brief evaluation of the Kyoto Protocol and three rival climate architectures in 
terms of some basic principles of equity, defined as the fair distribution of benefits and burdens amongst persons with competing claims. The principles of equity relevant to climate politics take two contrasting forms (Banuri et al., 1996, pp.856; Paavola, Adger and Huq, 2006, pp.3ff).

Consequentialist principles evaluate acts and social policies according to their outcomes, such as the extent to which they promote equality or social welfare or are beneficial to the worst off in society. According to Article 2 of the United Nations Framework Convention on Climate Change (FCCC), the objective of international climate change policy is the 'stabilisation of greenhouse gas concentrations in the atmosphere at a level that would prevent dangerous anthropogenic interference with the climate system' (United Nations, 1995, p.5).

Procedural principles evaluate the equity of acts or social policies in terms of the legitimacy of the way they were brought about, for example that the decision-making procedures involved respected the equal status of all parties; and that the duties defined by agreements reflect the capacities and historical responsibilities of those they bind. According to Article 3.1 of the FCCC, international climate change policy must reflect the 'common but differentiated responsibilities and respective capabilities' of developed and developing countries (United Nations, 1995, p.3).

While all of the main climate architectures are promoted on the basis that they are consistent with procedural and consequentialist equity, important differences in emphasis emerge between the architectures in terms of the balance struck between procedure and outcome. The balance struck in each case has had a profound impact on the way in which rival architectures are received in terms of global appeal and legitimacy. Rival architectures can usefully be analysed in terms of their fit with four principles of equity:

- C1: A safe atmosphere: climate architectures (and the measures they involve) should aim to minimise 'dangerous climate change.' There is no consensus as to what constitutes dangerous climate change, or what level of global warming would trigger it since the idea has an irreducibly normative, as well as natural 
scientific, component (Schneider and Lane, 2006, p.7). However, a useful working definition can be found in terms of the aim to limit increases in atmospheric concentrations of $\mathrm{CO}_{2}$ to a doubling of their pre-industrial level of 280 parts per million (ppm). For comparison, atmospheric $\mathrm{CO}_{2}$ concentrations reached 377 ppm in 2004 - a 35 per cent increase on the preindustrial level (Keeling and Whorf, 2005).

- C2: Affordability: climate architectures should not be excessively costly to adopt for existing and subsequent generations. This is a complex issue, given that estimating the social and economic impacts of alternative climate responses rests not only on accurate models of climate change for different levels of $\mathrm{CO}_{2}$, but also of development, population growth, and migration (Tol, 2002, pp.48ff).

- P1: Universal participation: members of all countries should be represented in the construction of the climate architecture and its mechanisms and policies; and while future generations cannot participate directly, their interests should also be taken into consideration at all times.

- P2: Fair burden sharing: the costs of implementing the architectures and the measures they involve should reflect the differing contributions of each country (and its members) to present and future climate change as measured by their current and historical greenhouse emissions.

\section{The Kyoto Protocol}

The Kyoto Protocol, which entered into force on 16 February 2005, requires 39 developed countries to bring about an average of a 5.2 per cent cut in greenhouse emissions by 2012 relative to their 1990 levels. The emissions cuts required by the Protocol vary from country to country. The EU, for example, which accounts for roughly 21 per cent of current global emissions, must reduce its emissions by 8 per cent; whereas Russia, which accounts for 17 per cent of global emissions, is permitted to emit the same amount in 2012 as it did in 1990.

An important aspect of the Protocol was the introduction of three 'flexibility mechanisms' to lower the costs of achieving emissions reductions. 'Joint 
Implementation' provides emissions credits for developed countries that implement cooperative emissions reductions projects or remove carbon from the atmosphere through other mechanisms (Grubb et al., 1999, pp.155ff). A 'Clean Development Mechanism’ allows developed countries to implement projects that reduce emissions in developing countries in order to meet their commitment. Finally, 'Emissions Trading' enables developed countries to buy carbon credits from other countries with spare capacity to help meet their commitments.

The Protocol was refined by a series of COPs leading up to the United Nations Climate Change Conference, which took place in Montréal between 28 November and 9 December 2005. Negotiators in Montréal reached an agreement in principle to extend the terms of the Protocol beyond 2012. They also amended the Clean Development Mechanism by raising its budget to \$13 billion for 2006-07 and by offering further incentives to developed countries that invest in sustainable technologies in developing countries. Agreement was also reached to start a special fund for research on preparing the world for climate change that cannot be avoided and to implement tougher mechanisms of compliance to prevent backsliding (United Nations, 2005).

Despite such changes, the expanded and strengthened architecture that emerged in Montréal does not fare particularly well in equity terms. First, a number of analyses have indicated that the Kyoto Protocol, even if it is extended to cover emissions over the course of this century, would achieve very modest reductions in greenhouse emissions. One influential analyst of the original Protocol found that it would at best reduce global temperature by only $0.15^{\circ} \mathrm{C}$ by the year 2050 relative to a 'business as usual' scenario where no international agreement obtained, and it seems unlikely that the refined Protocol would herald substantially better results (Wigley, 1998).

Second, the scope of the Protocol, despite it having been ratified by over 140 countries, is limited. One problem is that developing countries continue to be exempt from binding emissions reductions targets. This is a problem because the $\mathrm{CO}_{2}$ emissions of a number of developing countries are expanding rapidly. China, for example, is now the world's third largest greenhouse emitter after the US and 
the EU. Key developed countries, such as the USA and Australia, remain outside of Kyoto architecture at least partly because they view Kyoto as unequitable on procedural grounds so long as developing countries such as China are not required to make emissions cuts. No substantial progress was made at Montreal on the issue of participation, despite the US team agreeing to participate in 'non-binding talks on long-term measures’ to combat climate change (United Nations, 2005).

Third, the complexity of the Protocol has created loopholes such that developed countries can meet their targets in ways counter to the ethos of the FCCC or escape penalty if they miss their targets (Aldy, Barrett and Stavins, 2003, pp.38182). One example involves the purchase of emissions credits from countries that will meet their targets as a result of contingent socio-economic factors, such as economic stagnation (Russia) or changes in energy production that began before 1990 (UK and Germany). Another example is the exploitation of the fortuitous location with a country's territory of 'greenhouse sinks', such as forests, which absorb $\mathrm{CO}_{2}$ or other greenhouse gases so they play no further warming role in the atmosphere. Many of the beneficiaries of the inclusion of sinks in the Protocol are developed countries associated with high historical emissions, such as Japan, Russia, Canada and Australia. In fact, a number of studies suggest that, far from bringing about a 5 per cent decrease in global emissions by 2012, the inclusion of sinks in the current climate regime may limit any cut in $\mathrm{CO}_{2}$ emissions to at best 2 per cent on 1990 levels by 2012 (Gardiner, 2004, p.34).

For all these reasons, the Kyoto architecture seems at best a useful first step in the fight against climate change. It might, if it attracts full compliance from developed countries, save many existing and future persons from extreme climate impacts in the further future, or delay dangerous climate change so that individuals and institutions in some countries can adapt to a modified climate system (DeSombre, 2004, pp.44ff; Singer, 2002, pp.22ff). Yet, it will not fulfil principle C1 for it will certainly not prevent $\mathrm{CO}_{2}$ concentrations passing the critical doubling level sometime in the next 100 years.

Relative to its modest benefits, the costs of implementing Kyoto throughout this century (P2) would be significant if not crippling to the world's economy. 
Interestingly, even critics of Kyoto do not usually claim that it would be unfeasibly expensive to implement. Bjørn Lomborg, for example, suggests that extending the terms of Kyoto throughout the century would mean that the world would have to wait one year to enjoy the economic prosperity it would have enjoyed in 2050 if no international action to combat climate change had been undertaken (Lomborg, 2001, 323; Singer, 2002, pp.23-4). Moving to Kyoto’s fit with procedural principles, we have seen that participation under the protocol (P1) is broad, despite the continued absence of the United States and Australia; and the basic terms of the architecture (P2) involve developing countries making sacrifices broadly in line with their historical and ongoing responsibility for greenhouse emissions.

\section{Kyoto Lite}

The 'Kyoto Lite' approach, advocated by the current US administration, advocates a series of voluntary targets for national greenhouse emissions as part of an approach designed to reduce the 'carbon intensity' of participating states. A state's carbon intensity is measured by the ratio of its emissions of $\mathrm{CO}_{2}$ relative to economic output. By the end of 2005, six states had signed up to the approach: the USA, Australia, China, India, South Korea and Japan, which together account for more than 50 per cent of current global emissions. The approach (which provides incentives to businesses to move away from carbon intense technologies, and technology transfer to the developing world) aims to reduce the carbon intensity of developed and developing economies through voluntary agreements.

One problem with Kyoto Lite is that, as economies become more efficient, they may experience a downward drift in their carbon intensity indices while emitting more and more carbon into the atmosphere. The consequence, as one commentator has argued, is that the approach 'might encourage innovation, but would not necessarily lead to real reductions. The world might simply head for the abyss more efficiently' (Pearce, 2005, p.13). Even putting this possibility aside, its modest aims and limited scope mean that an international climate response based Kyoto Lite would be ineffective in terms of preventing dangerous climate change. 
The approach could, however, bring some beneficial outcomes for existing and proximate generations in developed countries who will gain from modest reductions in climate risks and relatively uncompromised economic growth.

Kyoto Lite fails to respect any of our four principles of equity. In terms of principles C1 and C2, it will not, and indeed does not even aim to, prevent a doubling of $\mathrm{CO}_{2}$. As a result, it seems a reasonable conjecture that Kyoto Lite would be far from affordable in the long-term despite being less costly for many developed countries in the short-term than its competitors. The participation of a handful of states, and the lack of consultation with the developing world, means that Kyoto Lite is in clear violation of the principle of universal participation (P1); and the measures to be undertaken are not determined in line with a principle of fair burden sharing (P2).

\section{Kyoto Plus}

The 'Kyoto Plus' regime, supported by the European Union and a range of nongovernmental organisations, seeks to build on the existing Kyoto architecture whilst making a range of modifications. It would require much deeper cuts of developed country parties than those proposed in Montréal (up to 30 per cent by 2030) and introduce a new system of 'first-time' targets for developing countries, including the bigger emitters such as Brazil, China and India. The approach will also involve technology and financial resource transfer to developing countries (Pearce, 2005; International Climate Change Taskforce, 2005).

The Kyoto Plus regime is designed to come into force as the present regime expires in 2012, and would initially cover emissions until at least 2030. Beyond this point, a set of longer-term objectives and mechanisms would be adopted congruent with the aim of avoiding dangerous climate change. A crucial aspect of Kyoto Plus is that it aspires, in the longer term, to adopt the principle that each person on the planet possesses an equal right to use the absorptive capacity of the atmosphere. This principle, however, is not intrinsic to the initial architecture, which instead aims to achieve large cuts in greenhouse emissions based on an eclectic range of mechanisms and targets designed to prevent dangerous climate 
change. Because it involves significant cuts in developed country emissions, and real engagement of the developing world, Kyoto Plus would have a range of beneficial consequences relative to Kyoto and Kyoto Lite, although it would certainly cause significant economic disruption in developed and developing countries.

Perhaps the main problem with Kyoto Plus concerns its long-term efficacy. Because it would retain many structural features of the original Protocol - such as the setting of national emissions targets on the basis of case-by-case negotiation, rather than by scientific analyses of what levels of $\mathrm{CO}_{2}$ can be considered safe - it is likely that it would only delay the onset of dangerous climate change. It seems, therefore, inconsistent with principles C1 and C2 since, as we see below, there are alternative architectures that would more efficiently safeguard the climate system bequeathed to future generations. Moreover, while the approach maintains a much

more even balance of procedure and outcome than Kyoto or Kyoto Lite, the emissions allocation process is still open to adjustment by parties who enjoy unequal negotiating positions with the result that the approach has intrinsically inequitable foundations. It is therefore in violation of principles of fair burden sharing (P2). Finally, the approach shares the wide, yet far from universal, participation profile of Kyoto, which calls into questions the fit with principle P1.

\section{Contraction and Convergence}

The third approach, 'Contraction and Convergence', has three main components. First, each person on the planet is granted an 'equal right to emit' greenhouse gases by virtue of their equal right to use the benefits provided by a shared atmosphere. This principle is treated as intrinsic to the architecture of the approach. Second, a 'global ceiling' for greenhouse emissions is set based on a calculation of the amount the atmosphere can withstand without dangerous climate changes emerging. Third, each country is allocated a yearly 'carbon emissions budget' consistent with the global ceiling not being exceeded, and calculated according to each country's population size relative to an agreed base year (Athanasiou and Baer, 2002, pp.47ff; Meyer, 2000, pp.56ff). 
The key aim is to bring about a stabilisation, and later a contraction, in global greenhouse emissions so that they stay below a safe level; and the idea that, in the longer term, all countries will converge on a roughly equal level of per-capita emissions compatible with the long-term stability of the climate system. Within this approach, a country that wants to emit more than its yearly quota must buy credits from countries that have spare capacity. The country selling the credits can then invest the receipts in activities enabling it to develop in a sustainable manner. This flexibility of the approach means that many developing countries will not be required to reduce their emissions to the same extent as developed countries even though there will be a cap on how much their emissions are permitted to grow. While 'emissions trading' is a key feature of all of the proposed successors to Kyoto, the trading zone under Contraction and Convergence covers the whole planet from the outset.

Unlike a number of competing approaches, Contraction and Convergence, if fully implemented, could be expected to reduce the risks of dangerous climate change substantially. Although the approach would be more costly to implement than its rivals in the short- to medium-term, it sits more easily with principles C1 and C2 than its rivals when we focus on the longer-term. It also has the merit that, because it adopts emissions targets based on scientific criteria for protecting the atmosphere, it reduces the role of power politics in determining the structure of the regime. The approach still involves a certain amount of horse-trading associated with the selection of the base year (as well as with the specific details of mechanisms concerned with emissions trading and the role of sinks) but much less than with rival architectures. Moreover, the 'convergence' part of 'contraction and convergence' at least partly deals with the need to achieve a fairer international distribution of the benefits associated with $\mathrm{CO}_{2}$ emissions. For all these reasons, this architecture seems to fit better with principle P2 than its rivals.

Finally, contraction and convergence also offers an interesting approach to the problem of historical responsibility, which has hitherto dogged attempts to construct a truly global solution to climate change to some developed countries (principle P1). Contraction and convergence, in being a fundamentally forwardlooking approach to climate change, does not allocate the most costly duties of 
climate mitigation and adaptation to developed countries because they are responsible for the emergence of climate change. Rather, it distributes the duties of climate management in line with their ability to undertake the protective measures deemed necessary to safeguard a future where dangerous climate change is avoided. As a result, Contraction and Convergence may prove more attractive, and therefore motivational, than rival architectures that appeal to the controversial historical duties members of developed countries possess as a result of the behaviour of their ancestors.

\section{Conclusion}

It is not an easy matter to apply principles of equity to the choice amongst alternative climate architectures in any definitive manner. Such principles are designed to operate in a wide range of circumstances and often seem better suited to the analysis of abstract examples rather than concrete policy problems, such as climate change. Climate change architectures, by contrast, are neither abstract nor designed to address all problems of distribution. Nevertheless, it is important to locate alternative architectures in the broader context of equity both for intrinsically ethical reasons and because only a truly equitable regime will secure popular legitimacy and support. Within this context, I hoped to have outlined an ethical framework by which alternative climate architectures might be evaluated in terms of equity, and that there is some reason to think that Contraction and Convergence represents modest progress at the level of outcomes and procedures. It is important to note that one issue that has not been fully addressed is the true extent of the economic disruption of climate architectures that aim for significant cuts in global greenhouse emissions. Until reliable models of the costs and benefits of adaptation and mitigation measures are produced, constructing an ethical analysis of competing architectures remains a tentative undertaking.

\section{Notes}

I would like to thank Simon Caney, Clare Heyward and two anonymous referees for Politics for their helpful comments on an earlier version of this paper. 


\section{References}

Aldy, J.E., Barrett, S., and Stavins, R.N. (2003) 'Thirteen plus one: a comparison of global climate policy architctures’, Climate Policy 3, pp.373-97.

Athanasiou, T. and Baer, P. (2002) Dead Heat: Global Justice and Global Warming, New York: Seven Stories.

Banuri, T., K. Göran-Mäler, M. Grubb, H.K. Jacobson and F. Yamin (1996) 'Equity and Social Considerations', in J. Bruce, H. Lee and E.F. Haites (eds.) Climate change 1995: Economic and Social Dimensions of Climate Change, Cambridge: Cambridge University Press, pp.79-124.

Barnett, J. (2002) The Meaning of Environmental Security. London: Zed Books.

Caney, S. (2005) 'Cosmopolitan Justice, Responsibility, and Global Climate Change', Leiden Journal of International Law 18, pp.747-75.

DeSombre, E.R. (2004) 'Global Warming: More Common Than Tragic', Ethics and International Affairs 18(1), pp.41-46.

Gardiner, S.M. (2004) 'The Global Warming Tragedy and the Dangerous Illusion of the Kyoto Protocol', Ethics and International Affairs 18(1), pp.23-39.

Grubb. M. with Vrolij, C. and Brack, D. (1999) The Kyoto Protocol, London: Earthscan.

International Climate Change Taskforce (2005) Meeting the Climate Challenge, London: Institute for Public Policy Research.

Keeling, C.D. and Whorf, T.P. (2005) 'Atmospheric CO2 records from sites in the SIO air sampling network', in US Carbon Dioxide Information Analysis Center, Trends: A Compendium of Data on Global Change (Oak Ridge, TN: US Department of Energy). Available online: http://cdiac.esd.ornl.gov/trends/co2/sio-mlo.htm.

Meyer, A. (2000) Contraction and Convergence: The Global Solution to Climate Change, Totnes: Green Books. 
Paavola, J., Adger, W.N, and Huq, S. 'Toward Justice in Adaptation to Climate Change', in W.N. Adger et al (eds) (2006) Fairness in Adaptation to Climate Change. Cambridge, MA: MIT Press, pp.1-19.

Page, E.A. (2006) Climate Change, Justice and Future Generations, Cheltenham, Edward Elgar.

Pearce, F. (2005) 'Tear up Kyoto or make it tougher’, New Scientist 28 May 2005, pp.12-13.

Schneider, S.H. and Lane, J. (2006) in H.J. Schellnhuber (ed) Avoiding Dangerous Climate Change, Cambridge, Cambridge University Press, pp.723.

Shue, H. (2001), 'Climate', in D. Jamieson (ed) A Companion to Environmental Philosophy, Oxford: Blackwell, pp.449-59

Singer, P. (2002) One World, London: Yale University Press.

Stripple, J. (2005) Climate Change After the International: Rethinking Security, Territory and Authority, Lund, Lund University Press.

Tol, R.S.J. (2002) 'Estimates of the Damage Costs of Climate Change', Environmental and Resource Economics 21, pp.47-73.

United Nations (1995) United Nations Framework Convention on Climate Change, London, HMSO Books.

United Nations (2005) Decision -/CP.11 Dialogue on long-term cooperative to address climate change by enhancing implementation of the Convention (http://unfccc.int/files/meetings/cop_11/application/pdf/cop11_00_dialogue_on_longterm_coop_action.pdf). Accessed on 13 November 2006.

Wigley, T. (1998) 'The Kyoto Protocol' $\mathrm{CO}_{2}, \mathrm{CH}_{4}$ and Climate Implications', Geophysical Research Letters, 25(13), pp.2285-2288. 